\title{
Initial and subsequent angiographic outcome of percutaneous transluminal angioplasty performed on internal mammary artery grafts
}

\author{
Nobukazu Ishizaka, Yuko Ishizaka, Yuji Ikari, Takaaki Isshiki, Tsutomu Tamura, \\ Hisayoshi Suma, Tetsu Yamaguchi
}

\begin{abstract}
Objective-To estimate the initial outcome and incidence of restenosis of angioplasty of internal mammary artery grafts in a retrospective study.

Methods-The study population consisted of 46 patients (48 lesions) who underwent first balloon angioplasty within the internal mammary artery graft. Most (37/48) were at the distal anastomosis. A few (8/48) were in the graft body. Six patients with the evidence of angiographic restenosis underwent a second angioplasty.

Results-The success rate and the restenosis rate of the first angioplasty was $73 \%$ and $30 \%$ respectively. Of the 34 patients ( 35 lesions) with a successful first angioplasty, 30 underwent follow up angiography with a restenosis rate of $30 \%$ $(9 / 30)$. A second angioplasty was performed on six of the nine restenotic lesions, with a success rate of $83 \%$ and no restenoses. The percent diameter stenosis of the recipient native coronary artery was significantly greater in the restenosis group, at 75 (SD 27)\% v 89 (17)\%, p < 0.05 .

Conclusions-First angioplasty of 46 patients (48 lesions) within an internal mammary artery graft was performed with a success rate of $73 \%$ and a restenosis rate of $30 \%$ (follow up rate of $88 \%$ ). The extent of the stenosis of the recipient native coronary artery may affect the restenosis rate.
\end{abstract}

(Br Heart f 1995;74:615-619)

Cardiology and

Cardiovascular

Cardiovascular

Memorial Hospita

Tokyo, Japan

N Ishizaka

Y Ishizaka

Y Ikari

T Isshiki

T Tamura

H Suma

The Third Department of Internal Medicine,

Toho University School of Medicine, Ohashi Hospital, Tokyo, Japan T Yamaguchi

Correspondence to: Dr N Ishizaka, Division of Cardiology, Emory University School of Medicine, Atlanta, Georgia 30322, USA.

Accepted for publication 11 April 1995

Keywords: internal mammary artery graft, angioplasty, angiographic follow up

Arterial grafts are increasingly replacing venous grafts in coronary artery bypass graft surgery because of their prolonged patency and resistance to atherosclerosis. The left or right internal mammary artery, ${ }^{1}$ gastroepiploic artery, ${ }^{23}$ and inferior epigastric artery are all sources of such grafts. The success of coronary artery bypass using such arterial grafts is no less favourable than that using venous grafts. However, we recently observed an increasing need for angioplasty to treat stenotic arterial grafts, concomitant with the more frequent use of such arterial grafts. ${ }^{4}$ Previous investigators have reported the safety and the high success rate of percutaneous transluminal angioplasty of internal mammary artery grafts. ${ }^{5-10}$ However, the number of cases of angiographic follow up after successful performance of angioplasty of the internal mammary graft has been rather small.

In this retrospective analysis, we evaluated 46 patients (47 internal mammary arteries and 48 lesions) that required percutaneous transluminal angioplasty. We analysed the initial success of angioplasty and the incidence of restenosis at the time of follow up to determine the variables which predict initial success or restenosis.

\section{Methods}

PATIENT POPULATION

Between September 1987 and December 1993, 3436 consecutive Japanese patients underwent percutaneous transluminal coronary angioplasty at our hospital. In this series, 46 patients (47 vessels, 48 lesions) had undergone a first percutaneous transluminal angioplasty within an internal mammary artery, and comprised our study population. Excluded from this study were patients with angioplasties which were performed to the native coronary artery beyond the internal mammary artery graft. Six patients (six vessels, six lesions) with angiographically documented restenosis underwent a second angioplasty during the same period. The patients' clinical characteristics are shown in table 1. All procedures, that is, percutaneous transluminal coronary angioplasty and follow up coronary angiography, were performed after informed consent had been obtained from each subject.

\section{DEFINITIONS}

Table 1 Clinical and angiographic characteristics of patients who underwent first internal mammary artery angioplasty

\begin{tabular}{|c|c|}
\hline $\begin{array}{l}\text { Number of patients } \\
\text { Age (years) } \\
\text { Number of grafts/lesions } \\
\text { Interval from bypass operation }\end{array}$ & $\begin{array}{l}46(38 \mathrm{M}, 8 \mathrm{~F}) \\
61(\mathrm{SD} 9) \text { range }(42-79) \\
47 \text { grafts, } 48 \text { lesions } \\
220(\mathrm{SD} 368) \text { range } 1-2136\end{array}$ \\
\hline IMA & left: 44 (45 lesions), right: 3 \\
\hline $\begin{array}{l}\text { The recipient native coronary } \\
\text { artery: }\end{array}$ & $\begin{array}{l}\mathrm{LAD} 45 \\
\mathrm{LCx} 2\end{array}$ \\
\hline Location of the lesion: & $\begin{array}{l}\text { Anastomosis } 37 \\
\text { Body } 8 \\
\text { Orifice } 3\end{array}$ \\
\hline
\end{tabular}

$\mathrm{LAD}$, left anterior descending coronary artery; LCx, left circumflex coronary artery. 
after angioplasty was the mean of two measurements of near orthogonal views. Arterial diameter was the mean of the most normal appearing segments.

Angiographic success was considered to be obtained when there was at least a $25 \%$ improvement in luminal diameter, and a final result with less than $50 \%$ stenosis.

$A$ concomitant dilatation of the native vessel was held to be present when a successful dilatation of the recipient native coronary artery as well as a successful graft dilatation was obtained.

Tortuosity of the graft was graded as mild, moderate, or severe. Mild tortuosity was defined as an isolated curve or series of bends in the graft proximal to the attempted lesion of $<90$ degrees. Moderate tortuosity was defined as an isolated curve or series of bends proximal to the attempted lesion of 90-120 degrees, and severe tortuosity was defined as an isolated curve or series of bends proximal to the attempted lesion of $>120$ degrees.

Angiographic restenosis was defined as a diameter stenosis of $>50 \%$ at a dilatation site shown on a restudy coronary angiogram.

\section{INDICATIONS FOR ANGIOPLASTY TO INTERNAL} MAMMARY ARTERY GRAFT

Patients with chest symptoms or with exercise testing suggesting myocardial ischaemia related to the luminal narrowing of the internal mammary artery graft were candidates for angioplasty to the graft.

\section{ANGIOPLASTY PROCEDURE}

All patients were given aspirin (80-325 mg) and a calcium antagonist orally at least three days before the angioplasty. At the beginning of the procedure, all patients were also premedicated with sublingual glyceryl trinitrate $(0.3 \mathrm{mg})$ and were given heparin, 100 units $/ \mathrm{kg}$, and lignocaine, $50 \mathrm{mg}$ intravenously. If the procedure took longer than one hour, additional intravenous heparin, half of the initial dose, was given to maintain the desired prolongation of activated clotting time. A 7F or $8 \mathrm{~F}$ catheter sheath was placed in either the right or the left femoral artery or the right brachial artery using a standard percutaneous technique. A standard guide catheter 8F JR4 (Schneider) or a 7F IMA (Schneider) was used in the angioplasty.

Coronary angiography and coronary angioplasty were performed by the standard Judkins approach. For angioplasty, we used two different systems: a guide wire/balloon catheter system and an over the wire/balloon catheter system. The system was selected according to the angiographic observations made before the angioplasty. In this series, one procedure used both systems. The balloon catheters were Probe $1.7 \mathrm{~F}$ (Bard) or Ace $1.8 \mathrm{~F}$ (SciMed) wire/balloon catheters (balloon diameter: $2 \cdot 0$ or $2.5 \mathrm{~mm}$ ) and Ten $2 \cdot 8 \mathrm{~F}$ (ACS) over the wire/balloon catheters (balloon diameter: 2.0 or $2.5 \mathrm{~mm}$ ). In some cases, wire/balloon catheters were used with a teleguide $4 \mathrm{~F}$ probing catheter having a $2.9 \mathrm{~F}$ internal diameter (Bard). When the lesion was insufficiently dilated following balloon dilatation, a larger balloon was used to obtain a greater dilatation.

\section{FOLLOW UP ANGIOGRAPHY}

A follow up angiography was performed at least three months after the procedure unless it was clinically indicated earlier. A repeat angioplasty was performed if there was an angiographic restenosis and if the patient had chest symptoms or positive exercise testing in relation to the luminal narrowing of the internal mammary artery graft. Patients who had a successful repeat angioplasty of the graft had a repeat angiogram at least three months later, unless clinically indicated earlier.

\section{STATISTICAL ANALYSIS}

Data are expressed as mean (SD). Differences were analysed by the $\chi^{2}$ test and Student's $t$ test. If the expected frequency was judged to be too small for the $\chi^{2}$, Fisher's exact probability test was performed.

\section{Results}

CLINICAL AND ANGIOGRAPHIC CHARACTERISTICS Clinical and angiographic characteristics of patients who underwent internal mammary artery graft angioplasty are given in table 1 . The mean interval between the coronary bypass operation and the first angioplasty of the internal mammary arterial graft was about seven months. Two patients underwent angioplasty of the internal mammary artery less than one week after the bypass operation. One of those patients underwent angioplasty the day after the bypass operation, while the other underwent angioplasty two days after the bypass operation. In each case, angioplasty was performed to the anastomotic site, and dilatation was successfully obtained without complications such as cardiac tamponade.

\section{OUTCOME OF FIRST ANGIOPLASTY}

Of the 46 patients (48 lesions), a successful first angioplasty was performed on 35 (35 lesions; $73 \%$ ). Seven (20\%) of the 35 patients with a successful angioplasty obtained a concomitant dilatation of the native vessel. Reasons for angioplasty failure were inability to cross the wire $(n=12)$ or an insufficient dilatation $(n=1)$. One patient underwent embolisation of a large side branch of the graft using gelatin particle and micro coils, as well as a balloon angioplasty of the anastomosis. ${ }^{11}$

\section{COMPLICATIONS}

No major complications were related to the procedure in this series; there were no instances of myocardial infarction, no need for emergency repetition of bypass surgery, and no deaths. One graft showed prolonged luminal narrowing after angioplasty, which did not respond to the intraluminal isosorbide dinitrate injection. Although this phenomenon was persisting at the time of angiography performed one day after angioplasty, luminal narrowing had disappeared spontaneously at the time of follow up angiography one week later, suggesting either prolonged vasospasm or distal 
Table 2 Comparison of angiographic and procedural variables of lesions with or without successful first angioplasty

\begin{tabular}{llll}
\hline Variable & $\begin{array}{l}\text { Success } \\
\text { (34 lesions) }\end{array}$ & $\begin{array}{l}\text { Failure } \\
\text { (14 lesions) }\end{array}$ & P value \\
\hline Left/right IMA graft & $33 / 1$ & $12 / 2$ & $\mathrm{NS}$ \\
Anastomosis/body/orifice & $27 / 4 / 3$ & $10 / 4 / 0$ & $\mathrm{NS}$ \\
Vessel diameter (mm) (SD) & $1.9(0 \cdot 5)$ & $2 \cdot 0(0 \cdot 3)$ & $\mathrm{NS}$ \\
Extent of luminal narrowing of the IMA graft & $1(3 \%)$ & $8(62 \%)$ & $<0.0001$ \\
$\quad$ Total occlusion & $3(9 \%)$ & $9(69 \%)$ & $<0.0001$ \\
$\quad \begin{array}{l}\text { Total or subtotal occlusion } \\
\text { Percent diameter stenosis }\end{array}$ & $70(17)$ & $83(12)$ & $\mathrm{NS}$ \\
Vessel tortuosity: & $21 / 13 / 0$ & $8 / 2 / 4$ & 0.003 \\
$\quad$ Mild/moderate/severe & & &
\end{tabular}

${ }_{\star}$ Total or subtotal occlusions are excluded.

embolisation of internal mammary artery graft. $^{12}$

\section{PREDICTORS OF INITIAL SUCCESS OF FIRST} ANGIOPLASTY

The preprocedural variables between lesions with or without successful first angioplasty are compared in table 2. Presence of total occlusion and high vessel tortuosity were significant predictors of failure $(P \ll 0.001, P<0.01$, respectively). The percent diameter stenosis was larger in the failure group than in the success group even after excluding total or subtotal occlusions; however, this was not statistically significant $(83 \%$ v $70 \%$ respectively, $P=0.08$ ).

\section{MANAGEMENT AFTER UNSUCCESSFUL FIRST ANGIOPLASTY}

None of the 14 patients (14 lesions) with an unsuccessful angioplasty received further intervention related to the graft. However, nine of the patients (that is, 9/14 lesions) underwent a successful balloon angioplasty to the recipient native coronary artery resulting in an alleviation of myocardial ischaemia.

\section{FOLLOW UP ANGIOGRAPHY AND OUTCOME OF} SECOND ANGIOPLASTY

Of the 34 patients ( 35 lesions) with a successful first angioplasty, 30 patients ( 30 lesions, $86 \%$ ) underwent follow up angiography. A follow up angiogram was obtained at a mean of 136 (SD 126) days (range 26-767 days). Angiographic restenosis was observed in nine patients (nine lesions; $30 \%$ ). Six of these patients underwent a second angioplasty, and in five this was suc-

Table 3 Comparison of the vessels with or without restenosis. Values are mean (SD) or $n$

\begin{tabular}{lcc}
\hline Variables & $\begin{array}{c}\text { Restenosis } \\
(9 \text { lesions) }\end{array}$ & $\begin{array}{c}\text { No restenosis } \\
(26 \text { lesions) }\end{array}$ \\
\hline Preprocedural angiographic variables & $9 / 0$ & $20 / 6$ \\
$\quad$ First/second angioplasty & $9 / 0$ & $25 / 1$ \\
$\quad$ Left/right IMA graft & $2 / 2 / 5$ & $2 / 3 / 21$ \\
Orifice/body/anastomosis & $2 \cdot 0(05)$ & $2 \cdot 0(0 \cdot 3)$ \\
Vessel diameter (mm) & $70(30)$ & $73(12)$ \\
Diameter stenosis (\%) & $5 / 4 / 0$ & $17 / 9 / 0$ \\
Vessel tortuosity, & & \\
$\quad$ mild/moderate/severe & $2 \cdot 3(0 \cdot 3)$ & $2 \cdot 3(0 \cdot 3)$ \\
Procedural variables & $1 \cdot 2(0 \cdot 3)$ & $1 \cdot 1(0 \cdot 2)$ \\
Balloon diameter (mm) & $9 \cdot 0(1 \cdot 9)$ & $9 \cdot 1(2 \cdot 6)$ \\
Balloon/vessel diameter ratio & $5 \cdot 9(4 \cdot 1)$ & $5 \cdot 0(2 \cdot 2)$ \\
Maximum inflation pressure (atm) & & \\
No of inflations & $25(13)$ & $19(13)$ \\
Postprocedural variables & $75(27)^{\star}$ & $89(17)^{\star}$ \\
Diameter stenosis (\%) & & \\
Diameter stenosis of recipient native coronary artery (\%) & &
\end{tabular}

IMA, internal mammary artery.

$\star \mathrm{P}<0.04$. cessful. The remaining three patients had no further intervention related to the internal mammary artery graft. All of the five patients (five lesions) with a successful second internal mammary artery angioplasty underwent follow up angiography, and none had a second restenosis.

PREDICTORS OF RESTENOSIS

Lesions with or without restenosis after a successful first or second angioplasty are compared in table 3. Among the variables examined, only the percent diameter stenosis of the recipient native vessel was significantly smaller in the non-restenosis group than in the restenosis group $(75 \% v 89 \%, \mathrm{P}<0.05)$.

\section{Discussion}

Recently, the internal mammary artery has been increasingly employed as a conduit for bypass because of its low incidence of atherosclerosis ${ }^{13-17}$ and high incidence of patency over a long period. ${ }^{17-22}$ Nevertheless, increasing numbers of patients are likely to experience stenosis within this graft. Repeat bypass surgery will be associated with some increase in risk because of disruption of the internal mammary graft, in addition to the risks observed in other instances of repeat bypass surgery. ${ }^{23}{ }^{24}$ Angioplasty to an internal mammary artery graft may be a good alternative to repeat bypass surgery in the case of graft stenosis.

\section{COMPARISON WITH PREVIOUS REPORTS}

There are several previous reports describing angioplasty of an internal mammary artery graft. ${ }^{5-10}$ The success rates were reported to be between $81 \%$ and $94 \%$ in previous reports describing more than 10 internal mammary artery angioplasty procedures. When other studies which described less than 10 angioplasties are included, the success rate was $92 \%$ (184/201)..$^{5-1025-36}$ The overall success rate of first angioplasty was relatively lower in the present study, which may be explained by our inclusion of $12 / 48(25 \%)$ totally or subtotally occluded internal mammary artery grafts. Most previous reports contained no or only a few cases with totally occluded internal mammary artery grafts. In our series, when we excluded occluded grafts the success rate of first angioplasty was $89 \%$, which is similar to the previous results. We earlier reported a success rate of $62 \%$ in the native coronary artery with chronic total occlusion. ${ }^{37}$ Compared with this rate, the success rate of angioplasty for a totally or subtotally occluded internal mammary artery graft was significantly lower (graft $v$ native coronary artery: $25 \% v 62 \%, \mathrm{P}<0.01$ ). Thus a totally or subtotally occluded internal graft appears to be less suitable for balloon angioplasty than a totally or subtotally occluded native coronary artery.

INTERVAL BETWEEN BYPASS OPERATION AND ANGIOPLASTY

It is helpful to know the interval between bypass operation and angioplasty during 
which one can safely perform angioplasty of the anastomotic lesion. In this series, one day was the shortest interval between bypass surgery and angioplasty. That patient developed chest pain immediately postoperatively, and a coronary angiogram showed stenosis at the site of anastomosis of the graft, which was successfully dilated on the first postoperative day. Another patient had a successful angioplasty two days postoperatively for anastomosis of internal mammary artery graft. Thus angioplasty to the distal anastomotic site of an internal mammary arterial graft may be feasible soon after bypass surgery.

\section{PREDICTORS OF INITIAL SUCCESS OF FIRST ANGIOPLASTY}

Vessel tortuosity was confirmed to be a significant predictor of angioplasty failure, as previously reported..$^{78}$ Two possible reasons for the development of such vessel tortuosity include: (1) coiling of a long internal mammary artery between the orifice and the anastomosis, and (2) presence of severe tortuosity of the internal mammary artery even before bypass surgery. At our hospital, the internal mammary artery is grafted with the surrounding pedicle; it is thus difficult to identify the major cause of tortuosity in each vessel. However, in the event that angioplasty is required, one should try to minimise the curve of the graft conduit during bypass surgery. No serious complications were related to angioplasty.

\section{INFLUENCE OF LUMINAL NARROWING OF RECIPIENT NATIVE CORONARY ARTERY ON GRAFT RESTENOSIS}

Among various angiographic factors examined, only the percent diameter stenosis of the recipient native coronary artery was found to be a significant predictor of restenosis. The presence of antegrade blood flow in the recipient native coronary artery is known to have an influence on the patency of the internal mammary artery graft after bypass operation. Some investigators have reported that an initially narrow or thin internal mammary artery graft increased its diameter when there was occlusion of the native vessel..$^{38}{ }^{39}$ Thus it is possible that antegrade flow in the recipient native coronary artery affects the restenosis rate of a successfully dilated internal mammary artery graft.

\section{CONCLUSION}

In conclusion, angioplasty of the internal mammary artery graft appears to be a safe and beneficial procedure, with success rates of $73 \%$ in the first angioplasty and $83 \%$ in the second angioplasty, and with angiographic restenosis rates of $30 \%$ in first angioplasty and none in second angioplasty. Presence of total or subtotal occlusion and a high degree of vessel tortuosity were predictors of angioplasty failure $(P \ll 0.001)$. The percentage of diameter stenosis of the recipient native coronary artery was significantly greater in the restenosis group, suggesting that it may affect the restenosis rate of successfully dilated internal mammary artery graft.
We thank Dr Minoru Ohno and Dr Wen-Maw Hwang for their comments.

1 Green GE. Internal mammary-coronary artery anastomosis: three year experience with 165 patients. Ann Thorac Surg 1972;14:260-71.

2 Suma H, Fukumoto H, Takeuchi A. Coronary artery bypass graft by utilizing in situ right gastroepiploic artery: basic study and clinical application. Ann Thorac Surg 1987;44:394-7.

3 Suma H, Takeuchi A, Hirota Y. Myocardial revascularization with combined arterial graft utilizing the internal mammary and the gastroepiploic arteries. Ann Thorac Surg 1989;47:712-5.

4 Isshiki T, Yamaguchi T, Tamura T, Saeki F, Furuta Y, Ikari Y, et al. Percutaneous angioplasty of stenosed gasIkari Y, et al. Percutaneous angioplasty of stenosed gastroepiploic

5 Sketch MH, Quigley PJ, Perez JA, Davidson CJ, Muhlestein JB, Herndon JE, et al. Angiographic followup after internal mammary artery graft angioplasty. $A m \mathcal{F}$ Cardiol 1992;70:401-3.

6 Hill DM, MacAuley BJ, Sheehan DJ, Simpson JB, Selmon MR, Anderson ET. Percutaneous transluminal of internal mammary artery bypass grafts [abstr]. $\mathcal{f} \mathrm{Am} \mathrm{Coll}$ Cardiol 1989;13:221A.

7 Shimshak TM, Giorgi LV, Johnson WL, McConahay DR, Rutherford BD, Ligon $\mathrm{R}$, et al. Application of percutaneous transluminal coronary angioplasty to the internal mammary artery graft. $\mathcal{f} \mathrm{Am}$ Coll Cardiol 1988;12: mammary

8 Dimas AP, Arora RR, Whitlow PL, Hollman JL, Franco I, Raymond RE, et al. Percutaneous transluminal angioRaymond RE, et al. Percutaneous transluminal angioplasty involving internal

9 Shimshak TM, Rutherford BD, McConahay DR, Giorgi LV, Johnson WL, Ligon RW. PTCA of internal mammary artery (IMA) grafts procedural results and late follow-up. Circulation 1991;84(suppl II):II-590.

10 Popma J, Cooke RH, Sleon MB, Stark K, Satler LF, Kent $\mathrm{KM}$, et al. Immediate procedural and long-term results of internal mammary artery angioplasty. $\mathrm{Am} \mathcal{f}$ Cardio 1992;69:1237-9.

11 Ishizaka N, Ikari $Y$, Saeki F, Ishizaka Y, Tamura $T$, Yamaguchi $\mathrm{T}$, et al. Repeat embolization of the side branch of the internal mammary artery graft by gelatin sponge particles and micro coils. Cathet Cardiovasc Diagn 1995;34:245-9.

12 Ishizaka $\mathrm{N}$, Ishizaka $\mathrm{Y}$, Ikari $\mathrm{Y}$, Tamura $\mathrm{T}$, Suma $\mathrm{S}$, Yamaguchi T. Prolonged luminal narrowing of internal mammary artery graft after percutaneous transluminal mammary artery graft after percur

13 Shelton ME, Foreman MB, Virmani R, Bajaj A, Stoney WS, Atkinson JB. A comparative study of the post-operaWS, Atkinson JB. A comparative study of the post-opera-
tive internal mammary grafts and saphenous vein corotive internal mammary grafts and saphenous vein coro-

14 Sims FH. A comparison of coronary and internal mammary arteries and implications of the results in the etiology of atherosclerosis. Am Heart $\mathcal{F}$ 1983;105:560-6.

15 Kay HR, Korns ME, Flemma RJ, Tector AJ, Lepley D. Atherosclerosis of the internal mammary artery. Ann Thorac Surg 1976;21:504-8.

16 Barbour DJ, Roberts WC. Additional evidence for relative resistance to atherosclerosis of the internal mammary artery compared to saphenous vein when used to increase myocardial blood supply. Am $\mathcal{F}$ Cardiol $1985 ; 56: 488$.

17 Lytle BW, Loop FD, Cosdgrove DM, Ratliff NB, Easley K, Taylor PC. Long-term (5 to 12 years) serial studies of internal mammary artery and saphenous vein coronary

internal mammary artery and saphenous vein coronary
bypass grafts. $\mathcal{F}$ Thorac Cardiovasc Surg 1985;89:248-58.
18 Loop FD, Lytle BW, Cosgrove DM, Stewart RW, Goormastic M, Williams GW, et al. Influence of the internal mammary graft on 10 year survival and other internal mammary graft on 10 year surviva

19 Kay EB, Naraphipour H, Beg RA, DeManey M, Tambe A Zimmerman HA. Internal mammary artery bypass graft: long term patency rate and follow-up. Ann Thorac Surg 1974;18:269-79.

20 Tector AJ, Davis L, Gabriel R, Gale H, Singh J, Flemma R. Experience with internal mammary artery grafts in 298 patients. Ann Thorac Surg 1976;22:515-9.

21 Okies JE, Page US, Bigelow JC, Krause AH, Salomon NW. The left internal mammary artery: the graft of choice. Circulation 1984;70(suppl I):I-213-21.

22 Grondin CM, Campeau L, Lesperance J, Enjalbert $M$ Bourassa MG. Comparison of late changes in internal mammary artery and saphenous vein grafts in two conmacutive series of patients 10 years after operation. secutive series of patients 10 years
Circulation 1984;70(suppl I):I-208-12.

23 Loop FD. A 20-year experience in coronary artery reoperation. Eur Heart $f$ 1989;10:(suppl H):74-84

24 Foster ED, Fisher LD, Kaiser GC, Myers WO. Foster ED, Fisher LD, Kaiser GC, Myers WO. Comparison of operative coronary artery bypass grafting:
the Coronary Artery Surgery Study (CASS) Registry
experience. Ann Thorac Surg 1984;38:563-70.

25 Bell MR, Holmes DR, Vliestra RE, Bersnahan DR. Percutaneous transluminal angioplasty of left internal Percutaneous transluminal angioplasty of left internal mammary artery grafts: two year's experience

26 Cote G, Myler RK, Stertzer SH, Clark DA, FishmanRosen J, Murphy M, et al. Percutaneous transluminal Rosen J, Murphy M, et al. Percutaneous transluminal angioplasty of stenotic coronary artery bypass gat 
27 Pinkerton CA, Slack JD, Orr CM, VanTassel JW. Percutaneous transluminal angioplasty involving the internal mammary artery bypass grafts: a femora approach. Cathet Cardiovasc Diagn 1987;13:414-8.

28 Douglas JS, Gruentzig AR, King SB, Hollman J, Ischinge $\mathrm{T}$, Meier $\mathrm{B}$, et al. Percutaneous transluminal coronary angioplasty in patients with prior coronary bypass surgery. F Am Coll Cardiol 1983;2:745-54.

29 Stullman WS, Hilliard K. Unrecognized internal mammary artery stenosis treated by percutaneous angioplasty after coronary bypass surgery. Am Heart 7 1987;113:393-5.

30 Zaidi AR, Hollman JL. Percutaneous angioplasty of internal mammary artery graft stenosis: case report and discussion. Cathet Cardiovasc Diagn 1985;11:603-8.

31 Crean PA, Mathieson PW, Richards AF. Transluminal angioplasty of a stenosis of an internal mammary artery angioplasty of a stenosis of an in

32 Dorros G, Lewin RF. The brachial artery method to transluminal internal mammary artery angioplasty. Cathe Cardiovasc Diagm 1986:12:341-6.

33 Steffenino G, Meier B, Finci L, von Segesser L, Velebit V. Percutaneous transluminal angioplasty of right and left internal mammary artery grafts. Chest 1986;90:849-51.
34 Salinger $M$, Drummer E, Furey $K$, Blott-Silverman C, Franco I. Percutaneous angioplasty of internal mammary artery grafts stenosis using the brachial approach: a case report. Cathet Cardiovasc Diagn 1986;12:261-5.

35 Singh S. Coronary angioplasty of internal mammary artery graft. Am $\mathcal{F}$ Med 1987;82:361-2.

36 Kereiakes DJ, George B, Stertzer SH, Myler RK. Percutaneous transluminal angioplasty of left internal mammary artery grafts. Am $\mathcal{f}$ Cardiol 1985;55: $1215-6$.

37 Ishizaka N, Isshiki T, Saeki F, Ishizaka Y, Ikari Y, Abe J, et al. Angiographic follow-up after successful percutaneous coronary angioplasty for chronic total coronary occlusion: experience in 110 consecutive patients. Am Heart $\mathcal{f}$ 1994;127:8-12.

38 Dincer B, Barner HB. The "occluded" internal mammary artery graft: restoration of patency after apparent occlusion associated with progression of coronary disease. $\mathcal{f}$ Thorac Cardiovasc Surg 1983;85:318-20.

39 Kitamura S, Kawachi K, Seki T, Sawabata N, Morita R, Kawata T. Angiographic demonstration of no-flow anatomic patency of internal thoracic-coronary artery bypass grafts. Ann Thorac Surg 1992;53:156-9. 